d. They reflect impressions in the form of motor impulses.

3. The exact share which the spinal cord takes in the nervi-motor functions of the uterus, it is not possible, nor in. deed necessary, to determine. Whether it or the ganglia proper of the uterus exercise the preponderating influence, $i$. $e$., originate or reflect the greater share of motor impulses conveyed to the uterus, does not concern us very much. What we are interested in knowing is the manner of action of the centres in question.

The following modes of action of the spinal column are submitted.

$a$. It acts centrically, originating motor impulses which are conveyed to the uterus either by its own afferent nerves, or through the ganglia of the sympathetic.

$b$. It reflects impressions made upon the excitor nerves, in the form of motor impulses; and this, whether the impressions are made upon the excitor nerves of the uterus itself, or of some other organ or part of the body. The sudden application of heat or cold to the general surface of the body is productive of reflex contraction of the uterus; but such reflex actions are more easily set up by irritating the mammary nerves, or the nerves of organs lying in the vicinity of the uterus.

c. The spinal cord conducts motor impulses generated in the great ganglia of the brain, themselves the product of emotion, to the uterus; or conveys to the uterus, from the same sources, influences which suspend its contraction.

$d$. The spinal column conducts to the voluntary muscles those motor impulses which are the product of the will, and which we believe to be generated in the cerebral hemispheres (speaking in a strictly physiological sense); or possibly it transforms the cerebral act into motor impulses. And the uterus acts consensually with the voluntary muscles so set in action, in the same way as the heart acts consensually with voluntary muscles, or the iris with some of the muscles of the orbit, or the bladder with the diaphragm and abdominal muscles, or the muscles of the intestine with the same muscles, or indeed with the voluntary system of muscles generally.

$e$. The spinal column receives those influences of co-ordination of voluntary movements which we believe to be generated in the cerebellum.

4. The great ganglia at the base of the brain were spoken of as the fourth system of nervous centres concerned in the parturient act. They must be considered as generating motor impulses, subsequently to the act of perception performed by the hemispheres of the brain; or the act of perception by the hemispheres (I speak in a strictly physiological sense again) is followed by the issuing of influences from the great ganglia which exalt, depress, or suspend the contractions of the uterus.

5. The cerebral hemispheres would appear to be the percipients of impressions which are transformed into motor impulses in the great ganglia, and conducted from thence through the crura cerebri and the spinal column to the uterus; or by another route, viz., through the par vagum and the sympathetic. And, again, it would appear that the cerebral hemispheres are the instruments of the will, and, by the intervention of the spinal cord, set in motion those muscles with which the uterus acts consensually. It will be seen that the brain acts entirely in a centric manner. I have not referred to the medulla oblongata, nor to the sensory cerebral nerves, because the latter really belong to the medulla; and the medulla itself acts in a manner no way different from the spinal column as regards the act of labour.

6. The cerebellum acts only as a co-ordinator of those voluntary muscles with which the uterus acts consensually. As far as is known, its action is purely centric.

In some particulars, the account just given of the nervimotor actions of the uterus is different from any other with which I am acquainted. In most obstetric systems of the present day, there is a casual reference to the reflex nature of uterine contraction, as well as to the influence of the emotions on the uterus during labour. In Dr. Tyler Smith's recent course of lectures, the subject is more fully investigated than in any prior writings; but, admirable as his account is, an undue share of importance is ( $I$ would submit, with the greatest deference to such an authority) accorded to the spinal column, which is, in my opinion, only an accessory to the act of labour, though chief accessory.

Intimately connected with the foregoing physiological particulars are some points in the pathology of uterine nervi-motor action.

14, Harewood Square.

\section{SUCCESSFUL SYSTEM OF DRAINAGE AT WORTHING.}

By Henry Coltet, M.D.

[Abridgement of a paper read before the South Eastern Branch, June 24th, 1857.]

As a branch of hygienic or preventive medicine, the subject of this paper cannot fail to interest general practitioners. The narrative may also prove an encouragement to other towns similarly situated to follow an example effecting so much good in the prevention of disease, in the increase in value of life and property, in domestic happiness, especially among the poorer classes, and, it may be hoped, an improvement in the mora and religious tone of society.

There are some now living in Worthing who remember it a small fishing village. It became a popular place of resort, and consequently increasing and prosperous, from the advantages of its position on the coast, its wide spread sands, and the varied beauty of the surrounding neighbourhood. As the population increased, however, the drainage, which was from the beginning without arrangement, and based upon the old polluting system of cesspools, proved defective. These poured their fluid contents by several trunks on the shore, a short dis. tance from the beautiful esplanade, which at times, therefrom, especially during the ebb of the tide, could no longer be re. sorted to.

Who, then, can be surprised that the town became injured in reputation as a watering place? But this was not all. The wells in many places became contaminated by soakage from the cesspools with which they were in close proximity, so that the water became thereby unfit for use. The requirements to remove these evils were a new system of drainage carried from the shore, and a general and sufficient supply of pure water. How it has been supplied, the following description of the works will show.

Drainage. The cesspools in the town (and there was one to almost every house) have been filled up, and water-closets have been substituted. The pernicious system of discharging the sewerage into the sea, in front of the town, has been aban doned. The drainage has been wholly remodelled; a main brick sewer or culvert, of an egg shape, measuring 3 feet 2 inches by 2 feet 3 inches, has been carried through the prin. cipal streets, at a depth, in some parts, of 23 feet; and is connected with the other streets, and with every house by branch drains of stone ware, varying in diameter from 15 inches to 6 inches. The main sewer terminates in a sumpt 6 feet 2 inches by 2 feet 10 inches; and a sewerage-well 30 feet deep and 10 feet in diameter at the top, reduced to 6 feet at the bottom. This well is situated considerably to the north-east of the town, and an artificial fall is obtained into it from every direction. In it is placed a sewerage-pump, consisting of three fifteen-inch barrels, worked by steam power, and connected with the engine in the water tower (shortly to be mentioned) by an iron shafting and driving gear, by which it is pumped through an outfall sewer emptying itself into the sea, at a place two miles eastward of the town, called Sea-Mills Bridge. There the sewerage mixes with a stream of pure water from the hills, and with the general drainage of the district. It is worthy of remalk, that the abundant supply of pure water, mixed as it now is with the sewerage, so completely, by its antiseptic properties, counteracts the putrefactive fermentation, that neither at the works, nor in the immediate neighbourhood of the outfall, is there any disagreeable smell. Thus the beach and sands are wholly freed from the sewerage which formerly damaged both them and the esplanade; the sands are rapidly improving, and will, it is expected, before long, recover their former firm and dry condition.

Water Supply. The water tower at the north-east of the town, with the engine-house and chimney shaft adjoining, have been erected under the direction of W. Rawlinson, C.E. It has a total elevation of about 110 feet, and measures 40 feet square on the plan. There is a central pier of brick, and a spiral staircase of cast iron. The foundation is of concrete. Within the adjoining engine-house, a well has been sunk in the chalk, to a depth of 70 feet, which is lined with iron cylinders, to exclude the sur. face water. Below this depth, a bore has been driven into the chalk 295 feet further, making a total depth of 365 feet; from it gushes an abundant supply of the purest water, 15 degrees of hardness, which is lifted by the engine into a water-tank at the top of the Tower, and thence distributed into all the houses in the town. The tank is of cast iron, 40 feet square, and 13 feet deep, and will contain 110,000 gallons. Its bottom is 70 
feet from the ground. The thickest plates are half an inch, and the thinnest three-eighths of an inch, in substance. The engine-which, as I have mentioned, also works the seweragepump in the sewerage-well, situated at a little distance-is a high pressure one, and was made by Messrs. Headley and Manning, of Cambridge. The engine commenced work at the end of last year (1856). The public sewers are all completed. The whole of that part of the town in which visitors reside is effectively drained and supplied with water, and the remaining works in the smaller streets are rapidly approaching completion. The poorest cottager has now, or shortiy will have, with respect to water-supply, all the advantages of his richer neighbours.

It is well known to visitors who have frequented the town, that a quantity of sea-weed is apt to be thrown upon the beach in the autumn. Except in combination with other substances which create chemical decomposition, it cannot be considered unhealthy, but remedial. The late Dr. Golding Bird was wont to remark that, but for the sewerage mixing with the sea-weed thrown on the shore, it would be an additional inducement to send patients to Worthing. The whole drainage having been removed, no deleterious action can again occur from this source.

With all the adverse circumstances which have been mentioned, the Registrar's report has not shown any unusual mortality in Worthing. The annual number of deaths has averaged from 15 to 17 per 1000 on the population for seven years, including many visitors. Of 417 deaths in the last three years, 39 only resulted from epidemic diseases. Cholera is wholly unknown. The daily range of the thermometer in three successive years, reported by the Registrar-General, from observations taken by Mr. W. G. Barker, of Worthing, was coequal with that for Ventnor, Torquay, Guernsey, Liverpool, etc.-the least in the kingdom. It was thus proved-1. That the town of Worthing, in all its natural relations, cannot be considered otherwise than a healthy locality, and a desirable place of re sort for invalids. 2. That the objections hitherto existing arose entirely from its defective drainage, and are now completely re moved by the new system just described.

I hope that, as the town has seriously suffered by the previous condemnation of my medical friends, they will now, as an act of justice to the inhabitants, and for the benefit of society make known its present altered and improved condition.

\section{F R A C T U R E OF TH E C R A N I U M.}

\section{By Henry Hancox, M.D., Wolverhampton.}

JoHx Surtr, aged 35 years, a strong, well built man, hy occupation a miner, when returning home from market, rather the worse for liquor, was attacked by a man, who threw a brick at him, which struck him on the left side of the head, a little above the orbital ridge of the frontal bone, producing a wound about two inches in length, with fracture of the bone. $\mathrm{He}$ fell and remained insensible for a few minutes, when he rose and walked home, a distance of about two hundred yards. An unqualified man attended him, and dressed the wourid, and continued to visit him for three weeks, the patient, during the whole of this time, being semiconscious. The fracture was not detected by the worthy attendant, who applied six blisters to the legs and other parts of the body. Occasional delirium on the part of the patient induced the quack to believe the man "mad," and to recommend his removal to the asylum. The friends, not willing to comply with the wishes of the attendant, summoned my brother, Mr. W. M. Hancox, to attend him. He found the patient in a semi-conscious state. The man answered questions when loudly spoken to ; the pupils acted freely; he referred all his sufferings to the head, pointing to the injured part as the seat of pain. On examining the head a fracture was distinctly detected, with depression of a frag. ment; on pressure being applied, the patient was thrown into convulsions, which led to the belief that a portion of bone was pressing on the brain. The operation of trephining was per formed by my brother, in the usual way, in the presence of $\mathbf{M r}$. Cooper and myself, when a small spiculum of bone, about an inch in length, was found penetrating through the dura mater into the substance of the brain; it was removed, the wound was brought together by plaster, and water dressing was applied to the parts.

The following day the patient was quite conscious, was able to speak and recognise those around him, and expressed himgelf thankful for the relief he had obtained. Ho continued to improve daily, and at the end of a month was able to go about, and gave evidence before the magistrates against the man who committed the assault.

From the above time he began to drink, and was attacked with inflammation of the brain, for which he was bled, and calomel, etc., was administered. He lingered for ten days, and died.

A post mortem examination was made forty-eight hours after death. The dura mater was quite healthy; on cutting through that membrane, lymph, in quantity about five or six ounces, was found to be pressing upon the brain, the left hemisphere of which was in a state of suppuration; the right hemisphere and cerebellum were slightly congested.

Remarks. This case presents a few points of interest. The circumstance of the man walking home after receiving so severe an injury, and shortly after reaching home becoming partially comatose, and remaining in that state for three weeks ; the complete success of the operation so long after the injury; and the restoration of consciousness to enable him to be questioned and cross-questioned by the magistrates, show the necessity of having recourse to every means in our power likely to prolong life or arrest disease. It may be stated, without fear of contradiction, that had it not been for his own imprudence in having recourse to stimulating drinks, his system at the time doubtless being debilitated and not sufficiently able to withstand the stimulating effects of alcoholic liquors, he might have been now living.

I am induced to send the above particulars on reading a similar case reported in the Journal of last week, by Dr. Clarke, of the Worcester Infirmary.

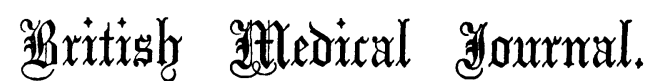

\author{
SATURDAY, JULY 11тH, 1857.
}

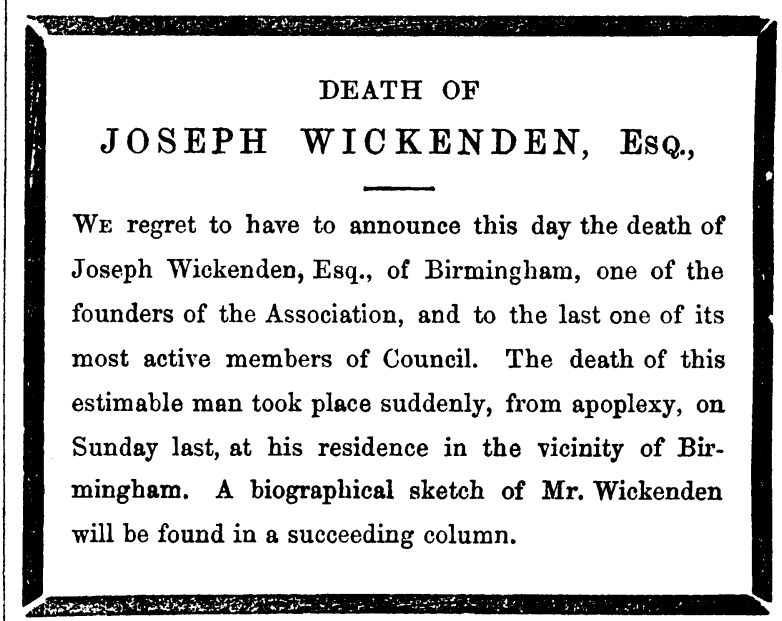

\section{THE TRIAL FOR POISONING AT GLASGOW.}

THE electric telegraph has this afternoon (Thursday) brought tidings that the jury, empanelled to try whether or not Madeline Smith treacherously and foully murdered her lover, Emile L'Angelier, have returned a verdict of "Not proven". Now that this interesting trial is concluded, we shall give in our next number a summary of the case in its medical bearings.

In the meantime, there are some remarks of practical interest, which may be offered at once. When Mr. Kesteven in this JourNal undertook to supply the antidote to the " poison. ing information," afforded to the public, with no evil intent of course, but still with evil' effect; by Chambers's Journal and 